\title{
Coping Responses During the COVID-19 Pandemic: A Cross-Cultural Comparison of Russia, Kyrgyzstan, and Peru
}

\author{
Ivan A. Voronin ${ }^{\mathrm{a}^{*}}$, Denisse Manrique-Millones ${ }^{\mathrm{b}}$, \\ Georgy M. Vasin ${ }^{c}$, Rosa Bertha Millones-Rivalles ${ }^{\mathrm{d}}$, \\ Oscar Manrique-Pino ${ }^{\mathrm{e}}$, Nataly Fernández-Ríos ${ }^{\mathrm{f}}$, Yulia A. Marakshina ${ }^{\mathrm{a}, \mathrm{c}}$, \\ Marina M. Lobaskova ${ }^{\mathrm{a}, \mathrm{c}}$, Elvira E. Symanyuk ${ }^{\mathrm{g}}$, Anna A. Pecherkina ${ }^{\mathrm{g}}$, \\ Irina A. Ageeva ${ }^{\text {h }}$, Irina A. Lysenkova ${ }^{\text {h, }}$ Victoria I. Ismatullina ${ }^{\text {a,c }}$, \\ Maria A. Sitnikova ${ }^{\mathrm{c}}$, Sergey B. Malykh ${ }^{\mathrm{a}, \mathrm{c}}$ \\ a Psychological Institute of Russian Academy of Education, Moscow, Russia \\ ${ }^{\mathrm{b}}$ Universidad de San Martín de Porres, Lima, Perú \\ ${ }^{c}$ Center of Interdisciplinary Research in Education of Russian Academy of Education, \\ Moscow, Russia \\ ${ }^{\mathrm{d}}$ Universidad de Lima, Lima, Perú \\ ${ }^{e}$ Universidad Católica Sedes Sapientiae, Lima, Perú \\ ${ }^{\mathrm{f}}$ Universidad Nacional de San Agustín de Arequipa, Arequipa, Perú \\ ${ }^{g}$ Ural Federal University, Institute of Humanities, Yekaterinburg, Russia \\ ${ }^{\mathrm{h}}$ Kyrgyz Russian Slavic University, Bishkek, Kyrgyzstan \\ * Corresponding author. E-mail: ivan.a.voronin@gmail.com
}

Background. The COVID-19 pandemic has subjected people around the world to severe stress, evoking a variety of coping responses. Coping responses can be broadly classified into four strategies: 1) problem-focused coping; 2) emotionfocused coping; 3) socially supported coping; and 4) avoidance. While there is a wide variability of individual coping responses, to some extent they are also culturally specific.

Objective. This study aimed to compare the differences in the prevalence and factor structure of coping responses during COVID-19 pandemic in three countries: Russia, Kyrgyzstan, and Peru.
Keywords: coping behavior; coping strategies; COPE; cross-cultural differences; factor structure. 
Design. The sample included 501 participants from Russia, 456 participants from Kyrgyzstan, and 354 participants from Peru. The mean age of participants was 28 years in Russia $(\mathrm{SD}=13.5)$; 24 years in Kyrgyzstan $(\mathrm{SD}=10.0)$; and 30 years in Peru (SD = 12.3). In Russia and Kyrgyzstan, coping strategies were assessed with an abbreviated Russian adaptation of the COPE (Coping Orientations to Problems Experienced) questionnaire. In Peru, coping responses were assessed using the Spanish version of the Brief COPE questionnaire. The average scores from fifteen COPE scales were used as the input data for linear modelling and factor analysis.

Results. The coping scores varied substantially within each country. Differences between countries accounted for $17.7 \%$ of the total variability in religious coping; $15.8 \%$ in acceptance; $13.9 \%$ in mental disengagement; and less than $7 \%$ in the other coping strategies. No difference in the prevalence of coping responses was found between Russian and Kyrgyz participants after accounting for age and gender. In all three countries the coping responses were associated with the same four coping domains: problem-focused coping, socially supported coping, avoidance, and emotion-focused coping. Four factors explained up to $44 \%$ of the total variation in the COPE scores. Religious coping and mental disengagement were classified into different coping domains in the three countries.

Conclusion. The results suggest that during the COVID-19 pandemic, people from different countries apply the full range of coping responses within the four universal coping strategies. Religious coping and mental disengagement differed the most across the countries, suggesting that some coping behaviors can take on different roles within the system of coping responses to stressful events. We attribute these differences to differing cultural and socioeconomic characteristics, and the different measures taken by governments in response to COVID-19.

\section{Introduction}

The COVID-19 pandemic has affected many aspects of people's day-to-day lives. The measures initiated by societies around the world to combat the spread of the virus have included obligatory home confinement and social distancing. The common sources of fear during the pandemic are: risk of infection of self and significant others; shortage of supplies; healthcare collapse; loss of income; global societal and financial crises; and the undefined duration of quarantine (Brooks et al., 2020; Mertens et al., 2020). The circumstances of the COVID-19 pandemic have led to a notable increase in individual anxiety, depression, and other symptoms of distress (Xie et al., 2020; Zacher \& Rudolph, 2020). It is therefore important to document a variety of coping responses that can allow people to overcome the stresses of the pandemic.

Coping refers to a range of behavioral and cognitive mechanisms (strategies) intended to deal with stress. To a great extent, modern understanding of coping responses follows the model proposed by R.S. Lazarus and S. Folkman (Biggs et al., 2017; Lazarus \& Folkman, 1984). That model portrays a coping response as an interaction between a person and his/her environment, as guided by a personal appraisal of the stress being experienced, and involving the mobilization of personal resources. 
Lazarus and Folkman (1984) identified two distinct methods of coping: 1) problem-focused coping, which aims to directly manage the source of stress, and 2) emotion-focused coping, which aims to regulate the emotions arising as a result of stressful events or situations. Later classifications extended this taxonomy by adding avoidant coping (resorting to distracting activities or denying the source of stress), and socially supported coping (resorting to advice, help, or emotional support from others) (Baumstarck et al., 2017; Carver et al., 1989; Litman, 2006).

The most commonly used questionnaire to measure coping behaviors is COPE, as developed by C.S. Carver (Carver et al., 1989). The COPE questionnaire measures 15 coping strategies:

1. Acceptance - submitting to the reality of the situation;

2. Active coping - active or direct actions to overcome a stressful situation;

3. Behavioral disengagement - refusal to actively deal with the stress;

4. Denial - refusing to believe in what happened or attempting to deny its reality;

5. Seeking emotional support - looking for empathy and understanding from others;

6. Humor - making jokes and laughing about the situation;

7. Seeking instrumental support - asking others for advice, help, or information;

8. Mental disengagement / Self-distraction - engaging in activities to get distracted from unpleasant thoughts associated with the problem, daydreaming, sleeping;

9. Planning - thinking about how to deal with a difficult life situation, developing strategies for action;

10. Positive reinterpretation - reappraising a stressful situation in a positive way;

11. Religion - appealing to the help of God, faith, religion, or meditation;

12. Restraint - keeping oneself from carrying out inconsiderate actions in response to the stress (not present in Brief COPE);

13. Substance use - using alcohol, drugs, or medications to get distracted from a stressful situation;

14. Suppression of competing activities - putting aside activities that do not help solve the problem (not present in Brief COPE);

15. Venting - expressing negative emotions.

The original COPE questionnaire included four items for each coping scale, thus 60 items in total. Later, a short version (Brief COPE) was developed that included 13 original scales: acceptance; active coping; behavioral disengagement; denial; emotional support; humor; instrumental support; self-distraction (originally mental disengagement); planning; positive reframing (originally positive reinterpretation); religion; substance use; and venting. It also added a self-blame scale (criticizing oneself for responsibility in the situation) (Carver, 1997). 
Brief COPE included two items for each coping scale, for 28 items in total. The COPE questionnaire became the most frequently used tool to assess coping strategies, having been used in $20 \%$ of all published research on coping between 2000 and 2013, including studies on coping with health issues, interpersonal stress, work stress, and caregiving (Kato, 2015).

Coping strategies have been studied all around the world. The occurrence and the structure of broad coping dimensions proved to be subject to cross-cultural differences, since culture both informs and limits effective approaches to overcoming stress (Sica et al., 1997). For example, in a study of stress coping in university students, Asian students were more likely to attempt religious coping than European students (Chai et al., 2012). Another study compared coping behaviors of Mexican citizens in the United States with Mexican-Americans and non-Hispanic citizens of the United States (Farley et al., 2005). Compared to other groups, Mexican citizens were less likely to engage in substance use or self-distraction, and more likely to use denial and religious coping. With regard to social support, Asian and Asian American individuals proved to be more reluctant to explicitly ask for support from others than European Americans (Kim et al., 2008).

Likewise, factor analysis of COPE and Brief COPE items and scales yielded heterogeneous results across different populations. For example, a three-factor structure was found in a Spanish sample using COPE: engagement, disengagement, and help-seeking (Gutiérrez et al., 2007). Four and five factors were found in French samples using Brief COPE: social support, problem solving, avoidance, and positive thinking (Baumstarck et al., 2017); and problem solving, support seeking, avoidance, cognitive restructuring, and distraction (Doron et al., 2014). Three factors were found using the Brazilian-Portuguese version of Brief COPE: religion and positive reframing, distraction, and external support (Brasileiro et al., 2016). Religious coping proved to be one of the most fluid strategies in terms of its relationship with other coping responses (Krägeloh, 2011).

A handful of research papers have addressed the individual differences in coping responses during the COVID-19 pandemic in different countries. The cultural nature of coping responses is noticeable in relation to the appraisal of the risk of the disease. A study in Vietnam showed that the perception of risk from COVID-19 was associated with social media usage and geography (Huynh, 2020). In Europe and United States, the fear of COVID-19 was positively associated with information intake from regular and social media, and was driven primarily by fear for loved ones and health anxiety (Mertens et al., 2020). A study in Germany showed that people used a full range of coping strategies in response to the COVID-19 pandemic (Zacher \& Rudolph, 2020). Problem-focused, emotion-focused, and socially supported strategies predicted higher levels of life satisfaction and positive affect in this study, and avoidant coping predicted higher levels of negative affect.

On the other hand, both problem-focused and avoidant coping predicted less anxiety, sleep problems, and cognitive alterations in response to home confinement in children and adolescents from Italy, Spain, and Portugal (Orgilés et al., 2020). The authors found that the most frequently used coping strategies in all three coun- 
tries were 1) accepting the reality of confinement; 2) engaging in social activities; 3 ) ignoring the events or acting as if nothing is happening; and 4) highlighting the positive aspects of staying at home. However, differences in coping responses were also discovered: Portuguese children more frequently reacted with humor; Spanish children more frequently collaborated with social activities, sought comfort from others, or acted as if nothing had happened; and Italian children more frequently seemed unworried.

The present study aims to extend the evidence on coping responses during the COVID-19 pandemic in different cultural and socio-economic contexts. We use data on coping strategies measured by the Russian and Spanish versions of the COPE questionnaire to 1) compare the occurrence of coping responses, and 2) describe the broad dimensions of coping strategies in three countries: Russia, Kyrgyzstan, and Peru.

\section{Methods}

\section{Participants and Procedure}

The study involved 501 participants from Russia (mean age 28 years, $76 \%$ female), 456 participants from Kyrgyzstan (mean age 24 years, $85 \%$ female) and 354 participants from Peru (mean age 30 years, 63\% female).

The data from Russia and Kyrgyzstan were collected as a part of a larger study that aimed to explore the psychological impact of the COVID-19 pandemic on students and teachers in regular schools, colleges, and universities. University students constituted a large majority of the Russian and Kyrgyz samples (69\% and $83 \%$ respectively). The other participants from Russia and Kyrgyzstan were university and school teachers. Likewise, the Peruvian data came from a larger study that aimed to explore the associations between metacognitions, coping strategies, and mental health during the COVID-19 pandemic. In total, 53\% of participants from Peru were university students. University students were on average younger than other participants, with lower variability of age in all three countries. A detailed account of sample characteristics is presented in Table 1.

The research projects in Russia and Kyrgyzstan received ethical approval from the corresponding institutional boards. Participants were eligible if they were over 18 years. They were informed about the anonymous and confidential nature of the research and gave informed consent before proceeding to fill out the questionnaires. Participation was voluntary and could be withdrawn by a participant at any moment without further explanation.

Responses were collected through an online survey. In Russia and Kyrgyzstan, participants were recruited by their educational organizations, which distributed the link to the online survey (Nikulchev et al., 2019, 2020). In Peru, the link to the survey was disseminated by the authors by an email invitation or through social media platforms (Facebook, WhatsApp, LinkedIn, etc.).

The Russian and Kyrgyz data were collected between May 11 and June 5, 2020. Peruvian data were collected between April 14 and June 5, 2020. 
Table 1

Sample summary

\begin{tabular}{|c|c|c|c|c|c|c|c|c|}
\hline \multirow[t]{2}{*}{ Country/group } & \multirow[b]{2}{*}{$\mathbf{n}$} & \multicolumn{4}{|c|}{ Age, years } & \multicolumn{3}{|c|}{ Gender, \% } \\
\hline & & $\mathbf{M}$ & SD & $\min$ & $\max$ & Male & Female & N/A \\
\hline \multicolumn{9}{|l|}{ Russia } \\
\hline All & 501 & 28.0 & 13.5 & 18 & 73 & 22.2 & 76.0 & 1.8 \\
\hline University student & 348 & 20.2 & 2.5 & 18 & 37 & 22.4 & 75.6 & 2.0 \\
\hline University teacher & 153 & 45.7 & 11.6 & 25 & 73 & 21.6 & 77.1 & 1.3 \\
\hline \multicolumn{9}{|l|}{ Kyrgyzstan } \\
\hline All & 456 & 23.8 & 10.0 & 18 & 80 & 13.8 & 85.1 & 1.1 \\
\hline University student & 378 & 20.0 & 1.9 & 18 & 30 & 12.7 & 86.2 & 1.1 \\
\hline University teacher & 23 & 48.3 & 13.7 & 22 & 69 & 17.4 & 82.6 & 0.0 \\
\hline School teacher & 55 & 39.4 & 11.7 & 22 & 80 & 20.0 & 78.2 & 1.8 \\
\hline \multicolumn{9}{|l|}{ Peru } \\
\hline All & 354 & 29.5 & 12.3 & 18 & 70 & 37.3 & 62.7 & 0.0 \\
\hline University student & 186 & 21.7 & 5.1 & 18 & 70 & 34.9 & 65.1 & 0.0 \\
\hline Other & 168 & 38.2 & 12.0 & 18 & 70 & 39.9 & 60.1 & 0.0 \\
\hline
\end{tabular}

\section{Materials}

To assess coping behaviors in Russia and Kyrgyzstan, we developed an abbreviated version of the COPE questionnaire (60 items, Carver et al., 1989) which had been adapted for Russian speakers by Rasskazova, Gordeeva, and Osin (2013). The Russian COPE questionnaire was abbreviated to meet time constraints in data collection in Russia and Kyrgyzstan. The items with the lowest factor loadings in Rasskazova et al. (2013) were omitted; the abbreviated version of the Russian COPE included 32 items from 14 COPE scales (the restraint scale was omitted entirely). Each scale was represented by 1 to 4 items. To assess coping behaviors in Peru, we used the Spanish adaptation of Brief COPE (Carver, 1997; Morán et al., 2010). The Spanish adaptation of Brief COPE included 28 items from 14 Brief COPE scales. Each scale was represented by two items. The number of items in each scale and their reliability are reported in Table 2.

Participants from Russia and Kyrgyzstan were asked to rate how often they used the ways of coping described by the COPE items. The stressor event was not overtly specified; however, since the preceding questionnaire in the battery referred to the participants' personal experience of COVID-19, we suggest that the responses to COPE were guided by this context. The participants were provided with four options: "I never do this," "I do this a little," "I do this quite a lot," and "I do this very often." The responses were recorded as integers in a range from 1 to 4 .

Participants from Peru were asked to rate their coping behaviors in response to lockdown. They responded by rating each item by an integer in a range of 0 to 3 , where $0=$ "I never do this," 1 = "I do this a little," 2 = "I do this a lot," and 3 = "I do 
this always." To make the responses comparable across the three countries, we relabeled the responses to correspond to a range of 1 to 4 and computed an average score for each original COPE scale as a sum of item scores, divided by the number of items in the scale.

Table 2

Reliabilities of COPE questionnaires used in the study

\begin{tabular}{|c|c|c|c|c|c|}
\hline \multirow{2}{*}{ COPE scale } & \multicolumn{3}{|c|}{$\begin{array}{l}\text { Russian COPE } \\
\text { (32 items) }\end{array}$} & \multicolumn{2}{|c|}{$\begin{array}{c}\text { Spanish Brief COPE } \\
(28 \text { items })\end{array}$} \\
\hline & $\mathrm{N}$ items & $\begin{array}{c}\text { alpha } \\
\text { (Russia) }\end{array}$ & $\begin{array}{c}\text { alpha } \\
\text { (Kyrgyzstan) }\end{array}$ & $\mathrm{N}$ items & $\begin{array}{l}\text { alpha } \\
\text { (Peru) }\end{array}$ \\
\hline Acceptance & 4 & 0.846 & 0.765 & 2 & 0.508 \\
\hline Active coping & 2 & 0.519 & 0.473 & 2 & 0.714 \\
\hline $\begin{array}{l}\text { Behavioral } \\
\text { disengagement }\end{array}$ & 2 & 0.315 & 0.488 & 2 & 0.609 \\
\hline Denial & 2 & 0.558 & 0.542 & 2 & 0.779 \\
\hline Emotional support & 2 & 0.732 & 0.720 & 2 & 0.759 \\
\hline Humor & 2 & 0.748 & 0.673 & 2 & 0.792 \\
\hline Instrumental support & 2 & 0.742 & 0.674 & 2 & 0.711 \\
\hline $\begin{array}{l}\text { Mental disengagement / } \\
\text { Self-distraction }\end{array}$ & 4 & 0.480 & 0.537 & 2 & 0.444 \\
\hline Planning & 2 & 0.706 & 0.660 & 2 & 0.489 \\
\hline $\begin{array}{l}\text { Positive reinterpretation/ } \\
\text { reframing }\end{array}$ & 2 & 0.810 & 0.741 & 2 & 0.557 \\
\hline Religion & 4 & 0.909 & 0.923 & 2 & 0.829 \\
\hline Substance use & 1 & - & - & 2 & 0.809 \\
\hline $\begin{array}{l}\text { Suppression of } \\
\text { competing activities }\end{array}$ & 1 & - & - & - & - \\
\hline Venting & 2 & 0.739 & 0.651 & 2 & 0.597 \\
\hline Self-blame & - & - & - & 2 & 0.543 \\
\hline
\end{tabular}

Note. COPE-32 is an abbreviated Russian adaptation of the original COPE (Rasskazova et al., 2013). COPE-28 is a Spanish adaptation of Brief COPE (Moran et al., 2010). alpha = Cronbach's alpha

\section{Analysis}

To compare coping behaviors across the three countries, we computed descriptive statistics (mean and standard deviations) for each COPE scale in each country. We applied a set of independent linear models to assess which part of the variability of COPE scores was accounted for by country (main predictor), and which by age, gender, and gender-by-country interaction (control variables). The interaction was included in the model to account for the uneven distribution of male and female participants across countries. We estimated marginal means in groups by 
gender, country, and gender-by-country, and performed pairwise post hoc comparisons by gender and country (Tukey's honestly significant difference test). To account for multiple testing, we adjusted significance thresholds by the number of models (15).

Taking into account the high heterogeneity of the broad coping dimensions across the populations, we chose to perform exploratory factor analysis to compare the factor structure of coping in all three countries. Guided by the scree plots, we extracted four factors using the minimum residual method with oblimin rotation. Factor loadings under 0.25 were not considered. Each COPE score was assigned to the factor on which it loaded the highest, except acceptance in Peru, which loaded to an equal extent on three factors and was assigned to the factor of emotionfocused coping (see Results section and Table 4c).

The data analysis was executed in $\mathrm{R}$, using the packages "emmeans" for estimated marginal means, and "psych" for factor analysis.

\section{Results}

\section{The Frequency of COPE Responses Across the Three Countries}

The summary statistics for the COPE scale scores are reported in Table 3. The most frequently reported coping behaviors were acceptance, active coping, planning, and positive reinterpretation, rated at the level of three points ("I do this quite a lot") in all three countries. The least frequently used coping behaviors in all countries were substance use, denial, behavioral disengagement, and religion, rated between one and two points ("I never do this" and "I do this a little"), except for religion in Peru. Peruvian participants scored religion well above two points (2.45). Another scale with low average score was self-blame, which rated about two points in Peru and was unavailable in the two other countries. The other COPE scales, such as emotional support, humor, instrumental support, mental disengagement, suppression of competing activities, and venting, yielded average scores of between two and three points ("I do this a little" and "I do this quite a lot").

The full model that included age, gender, country, and gender-by-country interaction explained under $20 \%$ of the total variability of the COPE scores. The model explained the least of the variability of instrumental support (2\%) and most of the variability of religion (19.7\%). The differences associated with age and gender of participants were under $5 \%$ of the total variability, with the least for mental disengagement $(0.3 \%)$ and the most for venting $(4.7 \%)$. Age differences were found for six COPE scales: older participants reported higher active coping $(\beta=0.006)$, planning $(\beta=0.010)$, religion $(\beta=0.009)$, and suppression of competing activities $(\beta=0.007)$, and lower mental disengagement $(\beta=-0.005)$ and venting $(\beta=-0.006)$, compared to younger participants. Gender differences were found for seven COPE scales: compared to male participants, female participants reported higher humor and self-blame, and lower denial, emotional support, instrumental support, religion, and venting (the marginal means are available from the corresponding author by request).

The degree of cross-cultural differences was captured by the variance by country after taking into account the age and gender of participants. Figure 1 shows 
the estimated marginal means of COPE scores in the three countries. Across the countries, participants differed the most in religion (17.7\%), acceptance (15.8\%), and mental disengagement (13.9\%). For the other scales, the degree of differences across countries was under 7\%. Compared to Russia and Kyrgyzstan, participants from Peru scored lower on behavioral disengagement, substance use, and venting, and higher on acceptance and mental disengagement. These scores did not differ between participants from Russia and Kyrgyzstan. Participants from Kyrgyzstan scored higher in denial than participants from Russia and Peru. The religion scores differed across all three countries: participants from Russia had the lowest score, participants from Kyrgyzstan had an intermediate score, and participants from Peru had the highest score.

Table 3

Descriptive statistics for COPE scales in the three countries

\begin{tabular}{lcccccc}
\hline \multirow{2}{*}{ Scale } & \multicolumn{2}{c}{ Russia } & \multicolumn{2}{c}{ Kyrgyzstan } & \multicolumn{2}{c}{ Peru } \\
\cline { 2 - 7 } & $\mathbf{M}$ & SD & M & SD & M & SD \\
\hline Acceptance & 2.90 & 0.64 & 2.75 & 0.64 & 3.41 & 0.53 \\
Active coping & 2.96 & 0.59 & 2.88 & 0.62 & 3.15 & 0.66 \\
Behavioral disengagement & 2.00 & 0.68 & 2.02 & 0.66 & 1.74 & 0.65 \\
Denial & 1.73 & 0.72 & 2.02 & 0.75 & 1.56 & 0.73 \\
Emotional support & 2.56 & 0.81 & 2.43 & 0.86 & 2.34 & 0.81 \\
Humor & 2.36 & 0.83 & 2.30 & 0.84 & 2.14 & 0.92 \\
Instrumental support & 2.37 & 0.84 & 2.34 & 0.83 & 2.35 & 0.78 \\
Mental disengagement & 2.42 & 0.59 & 2.41 & 0.60 & 2.94 & 0.70 \\
Planning & 2.98 & 0.68 & 2.95 & 0.72 & 3.02 & 0.62 \\
Positive reinterpretation & 2.81 & 0.81 & 2.82 & 0.82 & 3.00 & 0.70 \\
Religion & 1.49 & 0.72 & 2.03 & 0.98 & 2.45 & 0.97 \\
Substance use & 1.40 & 0.75 & 1.42 & 0.77 & 1.13 & 0.44 \\
Suppression of competing activities & 2.50 & 0.86 & 2.41 & 0.83 & - & - \\
Venting & 2.53 & 0.83 & 2.43 & 0.79 & 2.00 & 0.73 \\
Self-blame & - & - & - & - & 1.96 & 0.74 \\
\hline
\end{tabular}

Note. $M=$ mean score, $S D=$ standard deviation

The statistically significant contribution of gender-by-country interaction was found for acceptance, suppression of competing activities, and venting scores. Female participants from Peru scored higher on acceptance than male participants, but no difference between male and female participants was found in Russia and Kyrgyzstan. Female participants from Kyrgyzstan scored higher on suppression of competing activities, but no difference between male and female participants was found in Russia (there was no data from Peru for this COPE scale). Male participants from Russia and Kyrgyzstan scored higher in venting than female partici- 
pants, but no difference between male and female participants was found in Peru. Overall, the interaction accounted for at most $1.4 \%$ of total variability of COPE scores. The detailed account of the differences between the groups by country and gender is available upon request.

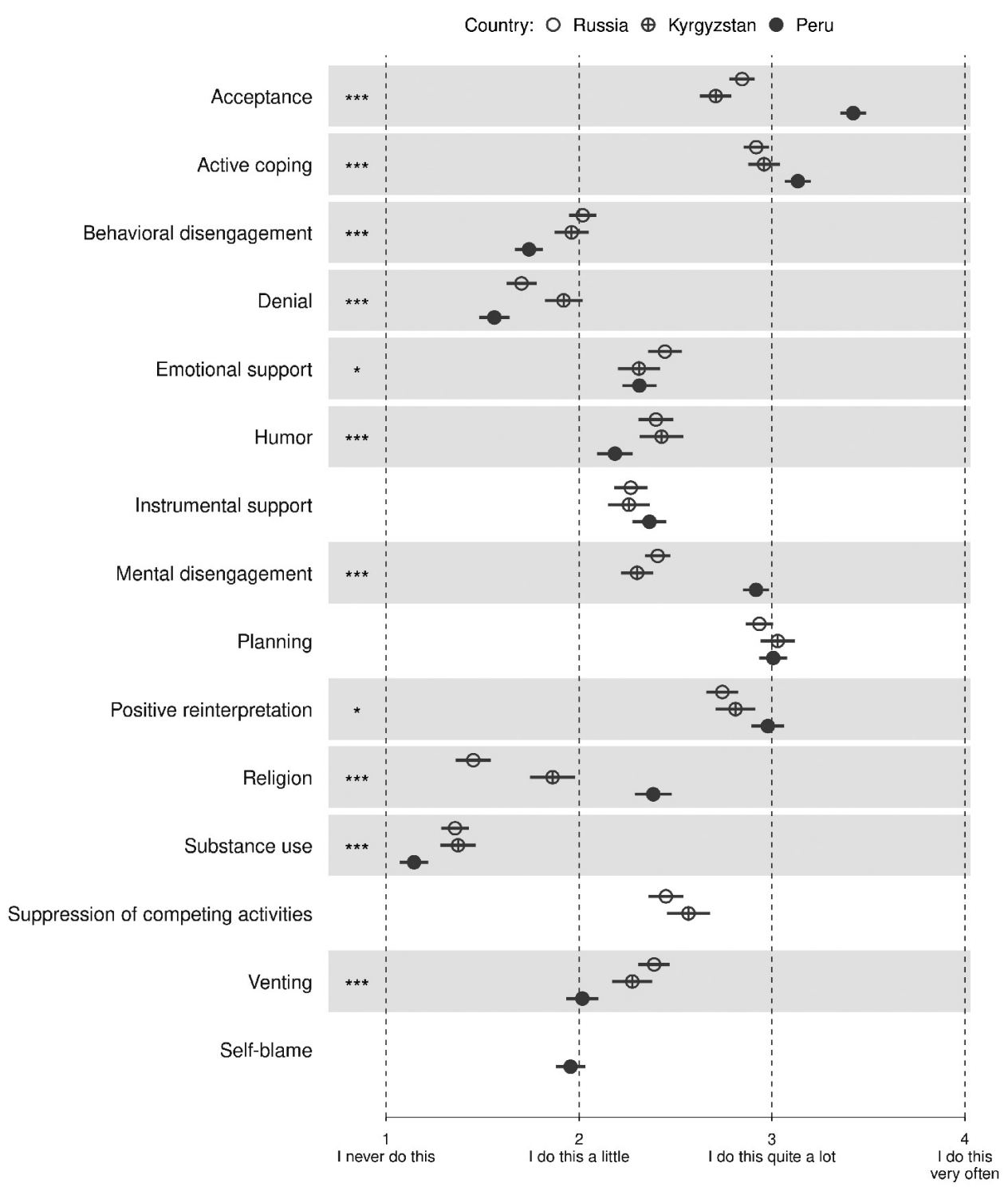

Figure 1. Estimated marginal means of COPE scores in Russia, Kyrgyzstan and Peru

Note. Error bars show $95 \%$ confidence intervals. Asterisks mark the statistical significance of country term: ${ }^{\star} \mathrm{p}<0.05,{ }^{\star *} \mathrm{p}<0.01,{ }^{* * *} \mathrm{p}<0.001$. All thresholds were Bonferroni-adjusted by the number of models (15). 


\section{The Factor Structure of COPE Responses}

The exploratory factor analysis of the COPE scores revealed that four factors explained $41.4 \%$ of the total variance in Russia, $40.8 \%$ in Kyrgyzstan, and $44 \%$ in Peru (Table 4). These four factors were problem-focused coping (F1), socially supported coping (F2), avoidant coping (F3), and emotion-focused coping (F4). All COPE scores loaded on at least one factor, except religion in Russia and substance use in Kyrgyzstan.

Problem-focused coping (F1) included active coping and planning in all three countries. In Russia and Kyrgyzstan, it was also associated with suppression of competing activities. In Peru, this factor included positive reinterpretation but not suppression of competing activities. In Kyrgyzstan, the factor of problem-focused coping (F1) was loaded negatively by behavioral disengagement.

The key variables for socially supported coping (F2) were emotional and instrumental support, which loaded on this factor in all three countries. In Russia and Kyrgyzstan, but not in Peru, this factor also included venting. In Peru, the factor of socially supported coping (F2) included emotional support, instrumental support, mental disengagement, and religion.

Denial was a key variable for avoidant coping (F3) in all three countries. In Russia, the avoidant coping factor also included mental disengagement, behavioral disengagement, and substance use. Similarly, in Peru this factor included behavioral disengagement and substance use as well as venting and self-blame. In Kyrgyzstan, avoidant coping (F3) included denial and religion.

Emotion-focused coping (F4) included humor and acceptance in all three countries; although, in Peru, acceptance loaded equally on the factors of problem-focused, avoidant, and emotion-focused coping. In Russia, this factor was also associated with positive reinterpretation; in Kyrgyzstan, with positive reinterpretation and mental disengagement.

The inter-factor correlations were similar in the Russian and Kyrgyz samples, ranging between 0.13 and 0.35 , with the exception of the smaller correlations between avoidant coping (F3) and emotion-focused coping (F4) [0.03 in Russia and 0.06 in Kyrgyzstan]. Problem-focused coping (F1) correlated positively with socially supported coping (F2) $[r=0.267$ and 0.205$]$ and emotionfocused coping (F4) [ $r=0.348$ and 0.247] in Russia and Kyrgzystan, respectively. The avoidant coping (F3) correlated negatively with problem-focused coping (F1) $[r=-0.181$ and -0.154$]$, but positively with socially supported coping (F2) $[r=0.354$ and 0.304$]$.

In the Peruvian sample, the inter-factor correlations were all positive and ranged between 0.01 and 0.33 . Socially supported coping (F2) was positively associated with the factors of problem-focused coping (F1) [ $\mathrm{r}=0.326]$, and avoidant coping (F3) $[r=0.246]$. The factor of emotion-focused coping (F4) was associated with the same two factors with weaker effect sizes $[r=0.113$ and 0.162 for F1 and F3, respectively]. Two correlations were robust across all three samples: problemfocused with socially supported coping (F1 and F2), and socially supported with avoidant coping (F2 and F3). 
Table 4

Exploratory factor analysis of COPE scales in three countries

(a) Russia

\begin{tabular}{|c|c|c|c|c|}
\hline factor/item & $\mathrm{F} 1$ & F2 & F3 & $\mathrm{F} 4$ \\
\hline \multicolumn{5}{|l|}{ F1 - Problem-focused coping } \\
\hline Active coping & 0.836 & & & \\
\hline Planning & 0.683 & & & \\
\hline Suppression of competing activities & 0.538 & & & \\
\hline \multicolumn{5}{|l|}{ F2 - Socially-supported coping } \\
\hline Emotional support & & 0.864 & & \\
\hline Instrumental support & & 0.760 & & \\
\hline Venting & & 0.493 & & \\
\hline \multicolumn{5}{|l|}{ F3 - Avoidant coping } \\
\hline Mental disengagement & & & 0.587 & \\
\hline Denial & & & 0.563 & \\
\hline Behavioral disengagement & -0.318 & & 0.411 & \\
\hline Substance use & & & 0.255 & \\
\hline \multicolumn{5}{|l|}{ F4 - Emotion-focused coping } \\
\hline Humor & & & & 0.636 \\
\hline Positive reinterpretation & 0.272 & & & 0.522 \\
\hline Acceptance & & & & 0.393 \\
\hline \multicolumn{5}{|l|}{ Religion* } \\
\hline Expl. var. (\%) & 13.5 & 12.4 & 7.8 & 7.7 \\
\hline
\end{tabular}

Note. The loadings under 0.25 were filtered out.

* This scale was not related to any of the factors.

(b) Kyrgyzstan

\begin{tabular}{|c|c|c|c|c|}
\hline factor/item & F1 & F2 & F3 & F4 \\
\hline \multicolumn{5}{|l|}{ F1 - Problem-focused coping } \\
\hline Planning & 0.735 & & & \\
\hline Active coping & 0.660 & & & \\
\hline Suppression of competing activities & 0.355 & & & \\
\hline Behavioral disengagement & -0.446 & & & \\
\hline \multicolumn{5}{|l|}{ F2 - Socially supported coping } \\
\hline Emotional support & & 0.836 & & \\
\hline Instrumental support & & 0.788 & & \\
\hline Venting & & 0.553 & & \\
\hline
\end{tabular}


F3 - Avoidant coping

Denial $\quad 0.879$

Religion $\quad 0.359$

F4 - Emotion-focused coping

Humor $\quad 0.569$

Acceptance $\quad 0.556$

$\begin{array}{lll}\text { Positive reinterpretation } & 0.389 & 0.425\end{array}$

Mental disengagement $\quad 0.365$

Substance use

\begin{tabular}{lllll}
\hline Expl. var. (\%) & 11.8 & 13.4 & 7.7 & 7.9
\end{tabular}

Note. The loadings under 0.25 were filtered out.

* This scale was not related to any of the factors.

(c) Peru

\begin{tabular}{lllll}
\hline factor/item & F1 & F2 & F3 & F4 \\
\hline
\end{tabular}

F1 - Problem-focused coping

Active coping $\quad 0.775$

Planning 0.773

Positive reinterpretation $\quad 0.385$

F2 - Socially supported coping

Emotional support $\quad 0.996$

Instrumental support $\quad 0.472$

Mental disengagement $\quad 0.363$

Religion $\quad 0.297$

F3 - Avoidant coping

Denial $\quad 0.800$

$\begin{array}{lll}\text { Venting } & 0.548 & 0.274\end{array}$

$\begin{array}{lll}\text { Self-blame } & 0.467 & 0.307\end{array}$

Behavioral disengagement $\quad 0.364$

$\begin{array}{ll}\text { Substance use } & 0.257\end{array}$

F4 - Emotion-focused coping

Humor $\quad 0.603$

\begin{tabular}{lcccc} 
Acceptance $^{*}$ & 0.436 & & -0.347 & 0.381 \\
\hline Expl. var. (\%) & 13.4 & 11.8 & 11.7 & 7.1
\end{tabular}

Note. The loadings under 0.25 were filtered out.

* This scale was assigned to the factor of emotion-focused coping despite the fact that it was also associated with problem-focused and avoidant coping to the similar extent. 


\section{Discussion}

We used data from Russia, Kyrgyzstan, and Peru to study cross-cultural differences in the prevalence and factor structure of coping strategies, as measured by Russian and Spanish adaptations of the COPE questionnaire. The scores on 15 COPE scales were used for cross-cultural comparison. Our results suggest that cross-cultural differences account for at most $20 \%$ of individual differences in coping responses, with religious coping, acceptance, and mental disengagement having the most variability across countries. Multiple coping responses were associated with the age and gender of the participants, with an overall effect under 5\%. The four broad coping strategies - problem-focused, emotion-focused, socially supported, and avoidant - were reproduced in all three countries. At the same time, some coping behaviors were classified into different categories in different countries; for example, religious coping was classified as a socially supported strategy in Peru, and an avoidant-coping strategy in Kyrgyzstan. It was not classified into any strategic category in Russia.

\section{Variability of coping behaviors within and between countries}

We observed the full range of responses on every item of the COPE questionnaire, as well as a wide variability of COPE scores in all three countries. The difference between countries, including gender-by-country interaction, explained up to $18 \%$ of the variability of COPE scores, with a higher explained percentage of variance for religious coping (17.7\%), acceptance (15.8\%), and mental disengagement (13.9\%). Other coping behaviors revealed almost no difference between countries, such as planning $(0.5 \%)$, seeking emotional and instrumental support $(1.1 \%$ and $1.0 \%$ respectively), suppression of competing activities (1.1\%), and positive reinterpretation $(1.3 \%)$.

The most prominent cross-cultural differences were observed in religious coping, which was the most common in Peru, less common in Kyrgyzstan, and the least common in Russia. We suggest that the high prevalence of religious coping in Peru can be explained by the fact that the Catholicism that is practiced by a majority of the Peruvian population (Instituto Nacional de Estadística e Informática, 2017) presents itself as a panacea for all worries, and it is a common practice in Peru to pray for relief from hardship and distress. In contrast, the religious practices of the Orthodox church, which is dominant in Russia (Pew Research Center, 2017) and Islam, which is dominant in Kyrgyzstan (Central Intelligence Agency, 2020), involve more of paying respect and devotion to spiritual beliefs and less of asking for support (Werth, 2011). However, religious coping is a complex construct that includes a variety of motivations and behaviors (Abu-Raiya \& Pargament, 2015); the data from the COPE questionnaire do not allow drawing more detailed conclusions about the nature of the differences in religious coping that we observed.

Noticeable cross-cultural differences were found for coping by acceptance and coping by mental disengagement, both of which were higher in Peru than in Russia and Kyrgyzstan. In Peru, acceptance was the most used coping response, with over $90 \%$ of Peruvian participants reporting that they had accepted the reality of the lockdown and had been learning to live with it. Acceptance and distraction were considered as relatively effective strategies for coping with unavoidable stress 
sources, such as acute or chronic pain and other health problems (Esteve et al., 2007; Kohl et al., 2013; Tamres et al., 2002).

We suggest that the critical trends in the COVID-19 infection and fatality rate, together with a strict lockdown, triggered a spike in the acceptance and disengagement coping responses in Peru. By the end of May 2020, when most of the data collection had been finished in all three countries, Peru had 148,285 confirmed cases and 4,230 deaths of COVID-19 per population of 33 million inhabitants (a fatality rate of $2.9 \%$ ). Russia had 405,843 confirmed cases and 4,693 deaths per population of 144.5 million (a fatality rate of $1.2 \%$ ). Kyrgyzstan had 1,748 confirmed cases and 16 deaths per population of 6.3 million (a fatality rate of $0.9 \%$ ) (World Health Organization, 2020). Previous research has shown a strong negative association between disengagement coping and perceived control (Cassaretto et al., 2003; Dijkstra \& Homan, 2016).

With the exception of religious coping, acceptance, and mental disengagement, the differences in coping responses across countries constituted only a small part of the total variability of coping. There have been only a few studies that compared the variability of coping within and between countries.

Gibson et al. (1992) compared coping behaviors reported by adolescents from 17 countries. The authors acknowledged that the adolescents from different countries reported similar problems and applied similar coping strategies. The most common coping response, regardless of country or socioeconomic grouping, was individual problem solving, such as trying harder or planning. Adolescents from Russia, treated as a separate group in the study and compared to adolescents from other countries, reported higher rates of trying harder as a response to the problems they met. A study of coping behaviors during COVID-19 in children and adolescents from Italy, Spain, and Portugal showed acceptance as the most prevalent coping strategy (Orgilés et al., 2020). The authors also found cross-cultural differences; the highest effect was found for collaborating with social activities, such as collective applause from the balconies that was a widespread expression of collective gratitude to health workers in Europe (Cramer's $\mathrm{V}=0.22$ ).

\section{Four Broad Coping Strategies in Russia, Kyrgyzstan, and Peru}

Our study reproduced the four broad dimensions of coping behavior that appeared in early studies of COPE (Litman, 2006 for the review), i.e., problem-focused, emotion-focused, social support, and avoidant coping strategies. In all three countries, active coping and planning were considered as problem-focused strategies; acceptance and humor as emotion-focused strategies; emotional and instrumental support as socially supported strategies; and denial as an avoidant strategy. The factor structure that we observed in the Russian sample is close to the one reported by Litman (2006) on a sample of 230 undergraduate students from the United States, who rated their coping responses using 60-items COPE. In Litman's study, the four coping factors loaded on the same COPE scores, but explained more of their variance (over 79\%). The patterns of inter-factor correlations were also reproduced in our study, with problem-focused, emotion-focused, and socially supported coping strategies more similar to each other than to avoidant coping. 
Unlike Litman, however, we observed a relatively high correlation between avoidant and socially supported coping, and this coefficient was one of the two correlations reliably reproduced in all three countries in our study. We suggest that avoidant coping might play an important role in a coping response to the COVID-19 pandemic and home confinement. Similarly, Rasskazova et al. (2013) suggest that, despite being considered a maladaptive coping strategy, avoidant coping can be essential when a stressful problem has no practical solution.

Two coping responses - religious coping and mental disengagement - were classified into different coping dimensions in all three countries. Religious coping was not associated with any coping factor in Russia, but was associated with avoidance coping in Kyrgyzstan, and with socially supported coping in Peru. Mental disengagement was associated with avoidance coping in Russia, but with emotionfocused coping in Kyrgyzstan, and with socially supported coping in Peru. This result, together with a relatively large cross-cultural difference in these coping behaviors, suggests that some coping behaviors can take different roles within the system of response to stressful events. This is especially relevant for religious coping, which can include a variety of strategies: religious reappraisal, seeking support from the religious community, emotional regulation through prayer or meditation, and/or finding new purpose in life (Pargament et al., 2000). The COPE questionnaire captures only a small part of the variability of religious coping behaviors.

\section{Implications for Further Investigation}

Our study aimed to document rather than explain the differences in coping responses during the COVID-19 pandemic. The nature and the consequences of the differences revealed in the study need to be further investigated.

For example, the cultural and socio-economic nature of coping response can be studied in relation to the appraisal of the risk of COVID-19 (Huynh, 2020, Mertens et al., 2020) Just as in the latest research (Zacher \& Rudolph, 2020, Orgilés et al., 2020), our study showed high prevalence of avoidant coping in response to COVID-19 pandemic. Avoidant coping is usually considered maladaptive in terms of subjective well-being (Benson, 2010; Bonneville-Roussy et al., 2017; Dijkstra \& Homan, 2016; Klostermann et al., 2011; Litman, 2006; Penley et al., 2002; Woodhead et al., 2014). Further study is needed to clarify the role and function of avoidant coping response in the context of global pandemic and related home confinement.

Our research provided evidence of gender differences in coping responses. Female participants reported higher degrees of humor and self-blame, and male participants reported higher degrees of denial, religion, venting, and emotional and instrumental support. The pattern of gender differences varied across countries for some coping responses; for example, female participants from Peru reported higher acceptance than male participants, but no gender differences were found in Russia and Kyrgyzstan. Gender differences overall accounted for a small percentage of the individual differences in coping responses.

Nevertheless, we regard gender differences in coping responses important for further investigation. According to a meta-analysis, women generally are more engaged in coping behaviors due to higher stress appraisal (Tamres et al., 2002). A 
qualitative study by Heltberg et al. (2013) showed that during global crises, women carry the additional burden of unpaid housework and meet harsher job conditions. In turn, Huang et al. (2020) reported that during the COVID-19 pandemic in China, women experienced more severe anxiety and fear than men.

\section{Conclusion}

Our study shows that, in general, participants from three different countries Russia, Kyrgyzstan, and Peru - report a wide variety of coping behaviors in response to the COVID-19 pandemic and home confinement. The differences between countries are most pronounced in religious coping, acceptance, and mental disengagement, all of which are the highest in Peru.

Coping responses aggregate into four broad dimensions: problem-focused, socially supported, emotion-focused, and avoidant coping. While the core coping behaviors replicate across the countries, others can load on different dimensions in different countries. Religious coping and mental disengagement were classified into different dimensions in all three countries. We attribute the differences in the prevalence of coping behaviors and their factor structure to cultural features (e.g., dominant religion and religious practices) and the specific conditions of the COVID-19 epidemic and lockdown in a country. Our results contribute to the collection of knowledge of individual responses to the COVID-19 pandemic around the world, and hopefully will aid the search for universal and culture-specific resources for coping with the consequences of the pandemic.

\section{Limitations}

The generalizability of our results is limited by the fact that most of our participants in all three countries were university students. It is possible that the occurrence of the reported coping behaviors is tied to specific aspects of the COVID-19 pandemic that students were exposed to, such as difficulties with learning online. For the same reason, behaviors associated with coping with caretaker stressors might be underrepresented.

Our study relied on self-reports of coping behaviors, and therefore might be subject to social desirability bias, especially the responses on substance use and religious coping. Another possible concern is that in the Russian and Kyrgyz samples, we used an abbreviated version of the COPE questionnaire that has never been used before. The reliability indices of the abbreviated COPE scales in Russian and Kyrgyz sub-samples were comparable to those achieved in Peru using the Spanish Brief COPE and were similar to the reliabilities reported in a big meta-analysis (Kato et al., 2015). We also suggest that the similarity in broad dimensions of coping yielded in Russia, Kyrgyzstan, and Peru supports the notion that similar constructs were measured in all three sub-samples.

\section{Acknowledgements}

This study was supported by Russian Foundation for Basic Research (Project No. 20-04-60394). 


\section{References}

Abu-Raiya, H., \& Pargament, K.I. (2015). Religious coping among diverse religions: Commonalities and divergences. Psychology of Religion and Spirituality, 7(1), 24-33. https://doi.org/10.1037/ a0037652

Baumstarck, K., Alessandrini, M., Hamidou, Z., Auquier, P., Leroy, T., \& Boyer, L. (2017). Assessment of coping: A new French four-factor structure of the brief COPE inventory. Health and Quality of Life Outcomes, 15(1), 8. https://doi.org/10.1186/s12955-016-0581-9

Benson, P.R. (2010). Coping, distress, and well-being in mothers of children with autism. Research in Autism Spectrum Disorders, 4(2), 217-228. https://doi.org/10.1016/j.rasd.2009.09.008

Biggs, A., Brough, P., \& Drummond, S. (2017). Lazarus and Folkman's Psychological Stress and Coping Theory. In C.L. Cooper \& J.C. Quick (Eds.), The Handbook of Stress and Health (pp. 349-364). John Wiley \& Sons, Ltd. https://doi.org/10.1002/9781118993811.ch21

Bonneville-Roussy, A., Evans, P., Verner-Filion, J., Vallerand, R.J., \& Bouffard, T. (2017). Motivation and coping with the stress of assessment: Gender differences in outcomes for university students. Contemporary Educational Psychology, 48, 28-42. https://doi.org/10.1016/j.cedpsych.2016.08.003

Brasileiro, S.V., Orsini, M.R.C.A., Cavalcante, J.A., Bartholomeu, D., Montiel, J.M., Costa, P.S.S., \& Costa, L.R. (2016). Controversies Regarding the Psychometric Properties of the Brief COPE: The Case of the Brazilian-Portuguese Version "COPE Breve." PLOS ONE, 11(3), e0152233. https:// doi.org/10.1371/journal.pone.0152233

Brooks, S.K., Webster, R.K., Smith, L.E., Woodland, L., Wessely, S., Greenberg, N., \& Rubin, G.J. (2020). The psychological impact of quarantine and how to reduce it: Rapid review of the evidence. The Lancet, 395(10227), 912-920. https://doi.org/10.1016/S0140-6736(20)30460-8

Carver, C.S. (1997). You want to measure coping but your protocol's too long: Consider the brief COPE. International Journal of Behavioral Medicine, 4(1), 92-100. https://doi. org/10.1207/s15327558ijbm0401_6

Carver, C.S., Scheier, M.F., \& Weintraub, J.K. (1989). Assessing coping strategies: A theoretically based approach. Journal of Personality and Social Psychology, 56(2), 267-283. https://doi. org/10.1037/0022-3514.56.2.267

Cassaretto, M., Chau, C., Oblitas, H., \& Valdéz, N. (2003). Estres y afrontamiento en estudiantes de psicologia [Stress and coping in psychology students]. Revista de Psicologia [Psychology Magazine], 21(2), 363-392.

Chai, P.P.M., Krägeloh, C.U., Shepherd, D., \& Billington, R. (2012). Stress and quality of life in international and domestic university students: Cultural differences in the use of religious coping. Mental Health, Religion \& Culture, 15(3), 265-277. https://doi.org/10.1080/13674676.2011.571665

Central Intelligence Agency. (2020). Central Asia: Kyrgyztan. Retrieved from: https:// www.cia.gov/library/publications/the-world-factbook/geos/kg.html

Dijkstra, M.T.M., \& Homan, A.C. (2016). Engaging in Rather than Disengaging from Stress: Effective Coping and Perceived Control. Frontiers in Psychology, 7. https://doi.org/10.3389/ fpsyg.2016.01415

Doron, J., Trouillet, R., Gana, K., Boiché, J., Neveu, D., \& Ninot, G. (2014). Examination of the Hierarchical Structure of the Brief COPE in a French Sample: Empirical and Theoretical Convergences. Journal of Personality Assessment, 96(5), 567-575. https://doi.org/10.1080/00223891.2014.886255

Esteve, R., Ramírez-Maestre, C., \& López-Martínez, A.E. (2007). Adjustment to chronic pain: The role of pain acceptance, coping strategies, and pain-related cognitions. Annals of Behavioral Medicine, 33(2), 179-188. https://doi.org/10.1007/BF02879899

Farley, T., Galves, A., Dickinson, L.M., \& Perez, M. de J.D. (2005). Stress, Coping, and Health: A Comparison of Mexican Immigrants, Mexican-Americans, and Non-Hispanic Whites. Journal of Immigrant Health, 7(3), 213-220. https://doi.org/10.1007/s10903-005-3678-5

Gibson, J.T., Baker, C.E., Showalter, S.M., Al-Sarraf, Q., Atakan, S.A., Borgen, W.A. ... Talyzina, N.F. (1992). Gender and culture: Reported problems, coping strategies and selected helpers of male and female adolescents in 17 countries. International Journal for the Advancement of Counselling, 15(3), 137-149. https://doi.org/10.1007/BF00116485 
Gutiérrez, F., Peri, J.M., Torres, X., Caseras, X., \& Valdés, M. (2007). Three dimensions of coping and a look at their evolutionary origin. Journal of Research in Personality, 41(5), 1032-1053. https:// doi.org/10.1016/j.jp.2007.01.006

Heltberg, R., Hossain, N., Reva, A., \& Turk, C. (2013). Coping and Resilience during the Food, Fuel, and Financial Crises. Journal of Development Studies, 49(5), 705-718. https://doi. org/10.1080/00220388.2012.746668

Huang, L., Xu, F.M., \& Liu, H.R. (2020). Emotional responses and coping strategies of nurses and nursing college students during COVID-19 outbreak [Preprint]. Public and Global Health. https://doi. org/10.1101/2020.03.05.20031898

Huynh, T.L.D. (2020). The COVID-19 risk perception: A survey on socioeconomics and media attention. Economics Bulletin, 40(1), 758-764.

Instituto Nacional de Estadística e Informática. (2017). Peru: Perfil Sociodemografico [Peru: Sociodemographic Profile]. Instituto Nacional de Estadística e Informática. Retrieved from: https://www. inei.gob.pe/media/MenuRecursivo/publicaciones_digitales/Est/Lib1539/

Kato, T. (2015). Frequently Used Coping Scales: A Meta-Analysis: Frequently Used Coping Scales. Stress and Health, 31(4), 315-323. https://doi.org/10.1002/smi.2557

Kim, H.S., Sherman, D.K., \& Taylor, S.E. (2008). Culture and social support. American Psychologist, 63(6), 518-526. https://doi.org/10.1037/0003-066X

Klostermann, K., Chen, R., Kelley, M.L., Schroeder, V.M., Braitman, A.L., \& Mignone, T. (2011). Coping Behavior and Depressive Symptoms in Adult Children of Alcoholics. Substance Use \& Misuse, 46(9), 1162-1168. https://doi.org/10.3109/10826080903452546

Kohl, A., Rief, W., \& Glombiewski, J.A. (2013). Acceptance, Cognitive Restructuring, and Distraction as Coping Strategies for Acute Pain. The Journal of Pain, 14(3), 305-315. https://doi. org/10.1016/j.jpain.2012.12.005

Krägeloh, C.U. (2011). A Systematic Review of Studies Using the Brief COPE: Religious Coping in Factor Analyses. Religions, 2(3), 216-246. https://doi.org/10.3390/rel2030216

Lazarus, R., \& Folkman, S. (1984). Stress, Appraisal, and Coping. Springer Publishing Company.

Litman, J.A. (2006). The COPE inventory: Dimensionality and relationships with approach- and avoidance-motives and positive and negative traits. Personality and Individual Differences, 41(2), 273-284. https://doi.org/10.1016/j.paid.2005.11.032

Mertens, G., Gerritsen, L., Duijndam, S., Salemink, E., \& Engelhard, I.M. (2020). Fear of the coronavirus (COVID-19): Predictors in an online study conducted in March 2020. Journal of Anxiety Disorders, 74, 102258. https://doi.org/10.1016/j.janxdis.2020.102258

Morán, C., Landero Hernández, R., \& González Ramírez, M.T. (2010). COPE-28: Un analisis psicometrico de la version en español del brief COPE [COPE-28: A Psychometric Analysis of the Spanish Version of the Brief COPE]. Universitas Psychologica, 9(2), 543-552. https://doi. org/10.11144/Javeriana.upsy9-2.capv

Nikulchev, E.V., Ilin, D.Yu., Kolyasnikov, P.V., Belov, V.A., Runtov, A.I., Pushkin, P.Y., ... Malykh, S. B. (2020). TSifrovaia platforma DigitalPsyTools dlia massovykh veb-oprosov v sisteme obrazovaniia [The Platform DigitalPsyTools for Mass Web-Surveys in Education]. Cloud of Science, 7(2). Retrieved from: https://www.researchgate.net/publication/340491972_Cifrovaa_platforma_ DigitalPsyTools_dla_massovyh_veb-oprosov_v_sisteme_obrazovania

Nikulchev, E.V., Ilin, D.Yu., Kolyasnikov, P.V., Ismatullina, V.I., Zakharov, I.M., \& Malykh, S.B. (2019). Razrabotka otkrytoi tsifrovoĭ platformy masshtabnykh psikhologicheskikh issledovanii [Development of the open digital platform for conducting large-scale psychological research]. Vestnik Rossiiskogo fonda fundamental'nykh issledovanii [Russian Foundation for Basic Research Journal], 4 (104). https://doi.org/10.22204/2410-4639-2019-104-04-105-119

Orgilés, M., Morales, A., Delvecchio, E., Francisco, R., Mazzeschi, C., Pedro, M., \& Espada, J.P. (2020). Coping behaviors and psychological disturbances in youth affected by the COVID-19 health crisis [Preprint]. PsyArXiv. https://doi.org/10.31234/osf.io/2gnxb

Pargament, K.I., Koenig, H.G., \& Perez, L.M. (2000). The many methods of religious coping: Development and initial validation of the RCOPE. Journal of Clinical Psychology, 56(4), 519-543. https:// doi.org/10.1002/(SICI)1097-4679(200004)56:4<519:AID-JCLP6>3.0.CO;2-1 
Penley, J.A., Tomaka, J., \& Wiebe, J.S. (2002). The Association of Coping to Physical and Psychological Health Outcomes: A Meta-Analytic Review. Journal of Behavioral Medicine, 25(6), 551-603. https://doi.org/10.1023/A:1020641400589

Pew Research Center. (2017, May 10). Religious Belief and National Belonging in Central and Eastern Europe. Pew Research Center's Religion \& Public Life Project. Retrieved from: https://www.pewforum.org/2017/05/10/religious-belief-and-national-belonging-in-central-and-eastern-europe/

Rasskazova, E.I., Gordeeva, T.Yu., \& Osin, E.N. (2013). Koping-strategii v strukture deiatel'nosti i samoreguliatsii: Psikhometricheskie kharakteristiki i vozmozhnosti primeneniia metodiki COPE [Coping strategies in the structure of activity and self-regulation: Psychometric properties and applications of the COPE inventory]. Psikhologiia. ZHurnal Vysshei SHkoly Ékonomiki [Psychology. Journal of the Higher School of Economics], 10(1), Article 1.

Sica, C., Novara, C., Dorz, S., \& Sanavio, E. (1997). Coping strategies: Evidence for cross-cultural differences? A preliminary study with the Italian version of coping orientations to problems experienced (COPE). Personality and Individual Differences, 23(6), 1025-1029. https://doi. org/10.1016/S0191-8869(97)00112-8

Tamres, L.K., Janicki, D., \& Helgeson, V.S. (2002). Sex Differences in Coping Behavior: A MetaAnalytic Review and an Examination of Relative Coping. Personality and Social Psychology Review, 6(1), 2-30. https://doi.org/10.1207/S15327957PSPR0601_1

Werth, P.W. (2011). Lived Orthodoxy and Confessional Diversity: The Last Decade on Religion in Modern Russia. Kritika: Explorations in Russian and Eurasian History, 12(4), 849-865. https:// doi.org/10.1353/kri.2011.0044

World Health Organization. (2020). Coronavirus Disease (COVID-19) Situation Reports. Retrieved from: https://www.who.int/emergencies/diseases/novel-coronavirus-2019/situation-reports

Woodhead, E.L., Cronkite, R.C., Moos, R.H., \& Timko, C. (2014). Coping Strategies Predictive of Adverse Outcomes among Community Adults: Coping Strategies and Adverse Outcomes. Journal of Clinical Psychology, 70(12), 1183-1195. https://doi.org/10.1002/jclp.21924

Xie, X., Xue, Q., Zhou, Y., Zhu, K., Liu, Q., Zhang, J., \& Song, R. (2020). Mental Health Status Among Children in Home Confinement during the Coronavirus Disease 2019 Outbreak in Hubei Province, China. JAMA Pediatrics. https://doi.org/10.1001/jamapediatrics.2020.1619

Zacher, H., \& Rudolph, C.W. (2020). Individual differences and changes in subjective wellbeing during the early stages of the COVID-19 pandemic. American Psychologist. https://doi. org/10.1037/amp0000702

Original manuscript received August 03, 2020

Revised manuscript accepted November 05, 2020

First published online December 30, 2020

To cite this article: Voronin, I.A., Manrique-Millones, D., Vasin, G.M., Millones-Rivalles, R.B., Manrique-Pino, O., Fernández-Ríos, N., Marakshina, Yu.A., Lobaskova, M.M., Symanyuk, E.E., Pecherkina, A.A., Ageeva, I.A., Lysenkova, I.A., Ismatullina, V.I., Sitnikova, M.A., Malykh, S.B. (2020). Coping Responses During the COVID-19 Pandemic: A Cross-Cultural Comparison of Russia, Kyrgyzstan, and Peru. Psychology in Russia: State of the Art, 13(4), 55-74. DOI: 10.11621/ pir.2020.0404 